\title{
HEALTHY EATING: L'APRENENTATGE DE LA LLENGUA ANGLESA PER PROJECTES
}

\author{
Arnau Boj Arqué. Mestre del CEIP Castell. Calafell \\ José Luis Alija García. Alumne de 3r curs de Magisteri de l'ensenyament de Llengua Estrangera. URV \\ Jacky Verrier Delahaie. Àrea de Didàctica de la Llengua i la Literatura. URV
}

\section{Introducció}

Aquest article presenta els resultats d'una activitat d'anglès realitzada per un alumne de l'especialitat de llengua estrangera (anglès) durant el Pràcticum II de tercer curs de la formació de mestres a la classe de segon curs de cicle superior del CEIP Castell de Calafell, sota la direcció dels seus tutors de pràctiques.

L'objectiu d'aquest treball ha estat ajuntar les metodologies actives -treball sobre projecte-, l'ensenyament de la llengua estrangera segons la perspectiva accional -realitzar una tasca en comú no exclusivament lingüística- del Marc europeu comú de referència per a les Ilengües: aprendre, ensenyar, avaluar (GENERALITAT DE CATALUNYA, 2003), la llengua com a conductor de continguts culturals $\mathrm{i}$ una estratègia didàctica que consisteix a treballar la llengua en funció de les necessitats comunicatives que requereix la situació d'aprenentatge i no per a i en ella mateixa.

El tema del treball és descobrir els costums alimentaris del col.legi. Les raons d'aquesta tria són les següents: a) es tracta d'un tema de gran actualitat en molts àmbits socials (educació, medicina i esports, entre altres); $b$ ) té un valor educatiu, ja que és una part del Marc europeu comú de referència per a les llengües (MECR, a partir d'ara); c) es presta bé a un treball sobre els continguts dels programes de llengua de les escoles; d) no requereix coneixements previs profunds, per la qual cosa es pot adaptar als diferents nivells de l'educació primària; e) exigeix competències transversals (informàtica, matemàtiques, redacció d'informes); f) s'insereix en una altra matèria d'aprenentatge com les ciències socials; $g$ ) permet contextualitzar -i així justificar- el treball sobre aspectes purament lingüístics; $h$ ) es pot obrir a recerques sobre comportaments alimentaris de diferents països, com indiquen les orientacions del MECR.

\section{L'ensenyament de les llengües estrangeres: entre llengua i comunicació \\ L'ensenyament de les llengües estrangeres neda entre dues aigües. Unes provenen de les orientacions del Consell d'Europa -Generalitat de Catalunya, 2003,}

i van Ek, 1975-, que recomanen que els objectius de les llengües estrangeres desenvolupin competències comunicatives, culturals $i$ educatives on la llengua sigui un instrument posat al servei de les necessitats d'aprenentatges i no un objectiu d'aprenentatge. Aquestes orientacions estan ben traduïdes als manuals, al llibre del professor i al llibre de l'alumne. Unes altres, però, mantenen la tradició didàctica a les classes i als quaderns d'exercicis, on es prioritza el coneixement, sobretot la gramàtica i el vocabulari.

Cap sorpresa, doncs, que a les classes hi hagi una situació paradoxal que alguns no dubten a anomenar esquizofrènica, on es produeix una barreja entre l'ús d'un manual de concepció comunicativa i avui accional (aprendre a fer i no solament a dir amb l'altre a través de la llengua) i una pràctica basada en l'aprenentatge de la llengua. Així, s'aprenen el nom dels aliments, les hores, els dies de la setmana, els colors, les parts del cos, els números fins a 10, etc. És evident que cap alumne es pregunta: per què he d'aprendre els dies de la setmana avui i no demà? De què em serveix saber els números de l'1 a 10 ? No es justifica, però és així, és la tradició. I aquesta tradició pesa molt. Hi ha un argument lingüístic per explicar aquesta situació: disposem d'una descripció de la llengua a través de la gramàtica i el diccionari i podem utilitzar una gran quantitat d'exercicis de llengua fàcils de fer a classe i fàcils de corregir immediatament, en què els alumnes poden veure immediatament els resultats de la seva feina. Però no hi ha cap descripció -diguem una gramàtica- de la comunicació, de les representacions culturals i dels comportaments socials en la llengua estrangera.

Tornem una mica sobre aquest tipus d'aprenentatge amb un exemple. Aprendre a dir l'hora en llengua estrangera està molt bé, però quina idea es fa l'alumne de I'hora en la cultura estrangera i en els comportaments dels locutors estrangers. Saber dir it's midday és una cosa, saber el que allò representa n'és una altra. I perquè it's midday no vol dir és migdia encara que les formes tenen semblances. D'aquí que el risc que corre l'alumne és de posar darrere aquestes expressions idees de la 


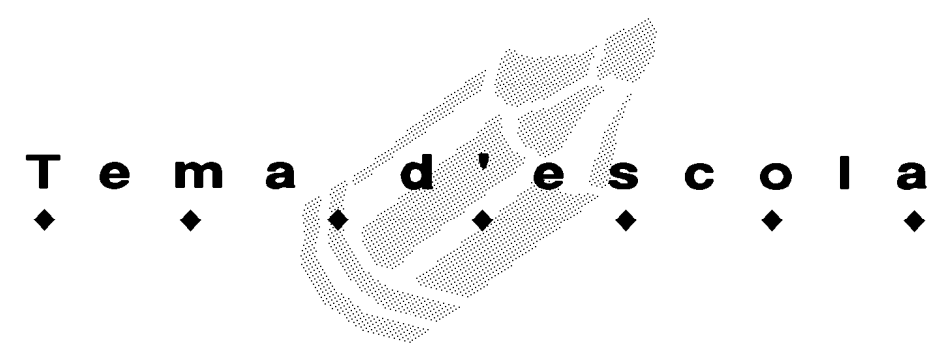

seva Ilengua materna. En altres paraules, podem dir que l'alumne parla en una llengua, la llengua estrangera, i pensa i es comporta en una altra, la llengua materna. A partir d'aquí, es planteja la qüestió del significat de les paraules. Com hom pot fer-se una idea de les paraules si no tenen valor per a l'alumne? Seria una mica com demanar als alumnes d'aprendre de memòria el nom dels rius d'un país sense cap referència, sense cap ancoratge cultural d'allò que representen. Dir que l'Ebre i el Mississipí són rius és en part veritat i en part fals, perquè per exemple les seves amplades són diferents i per tant les seves representacions mentals han de ser diferents també. És per l'experiència o el contacte suggestiu que es construeixen els coneixements. En la llengua passa exactament el mateix, i vet aquí, per exemple, per què la gramàtica, lluny de ser un objecte científic, és primer de tot un objecte cultural. Dit altrament, de què m'enriquiré més -ja que la qüestió és aquesta, l'enriquiment personal-: d'una visita en bus per una ciutat amb un guia que para cada vint minuts per fer quatre fotos a un monument, o d'un descobriment lent $\mathrm{i}$ insistent (escoltar, veure $\mathrm{i}$ tornar a veure, observar, sentir, tocar)? Ja heu respost, sens dubte.

\section{Donar significat a la llengua en la classe}

La pregunta següent és: llavors, què cal fer a l'aula? Diria més aviat: què es pot intentar fer perquè els alumnes se sentin més propers a la llengua estrangera, a la gramàtica i al vocabulari. Cal donar-los sentit, cal que les paraules i les estructures gramaticals parlin als alumnes. Tornem un moment sobre el tema de l'hora. Normalment, els alumnes aprenen les hores amb un gran rellotge de cartró enganxat a la pissarra on diu it's one o'clock, it's half past nine i passen les agulles. Des del punt de vista de la comunicació, el problema és que la resposta pot ser completament falsa si són les tres de la tarda.

Hem suggerit donar sentit a les paraules, a la gramàtica, a la llengua. Això és possible si es col-loca la llengua al servei d'una intenció comunicativa o accional, és a dir, si busquem un descobriment -allò que dóna sentit a l'aprenentatge per a l'alumne- utilitzant la llengua estrangera. Les aportacions de les metodologies mal anomenades innovadores aporten pistes de treball. Pensem simplement en un projecte -pot ser un problema a resoldre- que té l'avantatge de situar l'alumne davant un aspecte desconegut que li demana que assumeixi responsabilitats, perquè si el projecte no es porta a terme no hi ha descobriment ni aprenentatge. I quin paper hi juga la llengua en tot això? Cal presentar el lèxic $i$ la gramàtica abans de tirar endavant el projecte? Cadascú elegirà l'opció que li sembli més correcta, però seguint la concepció de l'aprenentatge ràpidament esbossada; l'apre- nentatge de la llengua ha d'anar en paral-lel a les necessitats de resolució del projecte.

Abordem ara les qüestions tècniques.

\section{Competències bàsiques, àrea principal $\mathrm{i}$ altres àrees 0 àmbits que es treballen}

Les competències pròpies de l'àrea de Llengua estrangera $i$ les aportacions que fa l'àrea a les competències bàsiques són les que es mostren a la taula 1 i que tot seguit s'especifiquen:

\begin{tabular}{|l|l|}
\hline $\begin{array}{l}\text { Competències pròpies } \\
\text { de l'àrea de Llengua } \\
\text { estrangera }\end{array}$ & $\begin{array}{l}\text { Aportacions de l'àrea a les } \\
\text { competències bàsiques }\end{array}$ \\
\hline $\begin{array}{l}\text { Competència comu- } \\
\text { nicativa lingüística i } \\
\text { audiovisual }\end{array}$ & $\begin{array}{l}\text { - Competència d'aprendre } \\
\text { a aprendre }\end{array}$ \\
$\begin{array}{l}\text { - Tractament de la informa- } \\
\text { ció i competència digital. } \\
\text { Competència social i ciu- } \\
\text { tadana }\end{array}$ \\
\hline
\end{tabular}

Taula 1. Competències pròpies de l'àrea de Llengua estrangera $\mathrm{i}$ aportacions a les competències bàsiques

Competència comunicativa lingüística i audiovisual:

- La competència oral: fer ús del llenguatge com a instrument de comunicació oral i escrita, que es desenvoluparà mitjançant activitats del qüestionari per conèixer els hàbits alimentaris dels seus professors, pares i companys.

- La competència escrita: ús d'estructures pròpies de la llengua estrangera per expressar els resultats de les enquestes de manera escrita.

- La competència discursiva: Apropament a textos i materials audiovisuals en format paper o digital que parlen sobre els hàbits alimentaris de persones d'arreu del món.

Competència d'aprendre a aprendre: Els alumnes reflexionen i potencien la seva iniciativa personal opinant sobre diferents aspectes referits a la dieta pròpia i de les persones que els envolten, per mitjà de diferents tècniques d'aprenentatge, com poden ser la realització de les preguntes del qüestionari, la discriminació d'informació no rellevant d'un text sobre els hàbits alimentaris o confeccionant una presentació en Power Point.

Competència en el tractament de la informació i competència digital: Els alumnes practiquen i es familiaritzen amb el funcionament dels cercadors per buscar informació a Internet sobre els hàbits alimentaris de les persones del país i d'arreu del món.

Competència social i ciutadana: Els estudiants aprenen a desenvolupar actituds positives en les relacions 


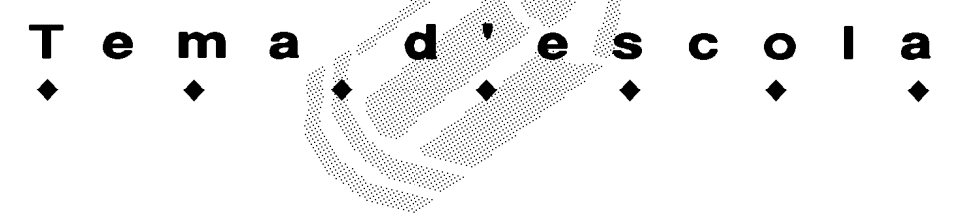

personals, com poden ser els gustos dels altres i el respecte per altres maneres d'entendre la vida i l'alimentació.

\section{Objectius d'aprenentatge}

- Buscar i trobar informacions sobre els hàbits alimentaris a l'escola i a l'entorn de l'alumne.

- Fer petits intercanvis comunicatius (diàlegs) per practicar les estructures de la unitat, les expressions i el vocabulari.

- Expressar-se oralment mitjançant l'entonació corresponent en situacions reals de comunicació.

- Extreure informació rellevant a partir d'enquestes sobre hàbits alimentaris i textos extrets d'Internet.

- Elaborar un informe sobre la informació que han recopilat a les enquestes i a Internet.

- Confeccionar una presentació en Power Point per a la seva exposició posterior a l'aula.

- Expressar-se oralment mitjançant l'entonació corresponent en una exposició oral a classe feta amb un programa d'ordinador a partir de la informació extreta sobre els hàbits alimentaris.

\section{Continguts}

Els continguts propis de la dimensió comunicativa són els següents:

\section{Parlar i conversar}

- Interacció oral a l'aula en situacions reals o simulacions.

- Formulació de preguntes i respostes a missatges.

- Exposició oral individual i en grup.

Escoltar i comprendre

- Identificació dels aliments que s'hi esmenten.

- Comprensió d'instruccions de treball i d'actuació a l'aula.

- Escolta i repetició de l'entonació de les diferents qüestions relacionades amb el menjar.

- Producció oral de textos elaborats pels alumnes

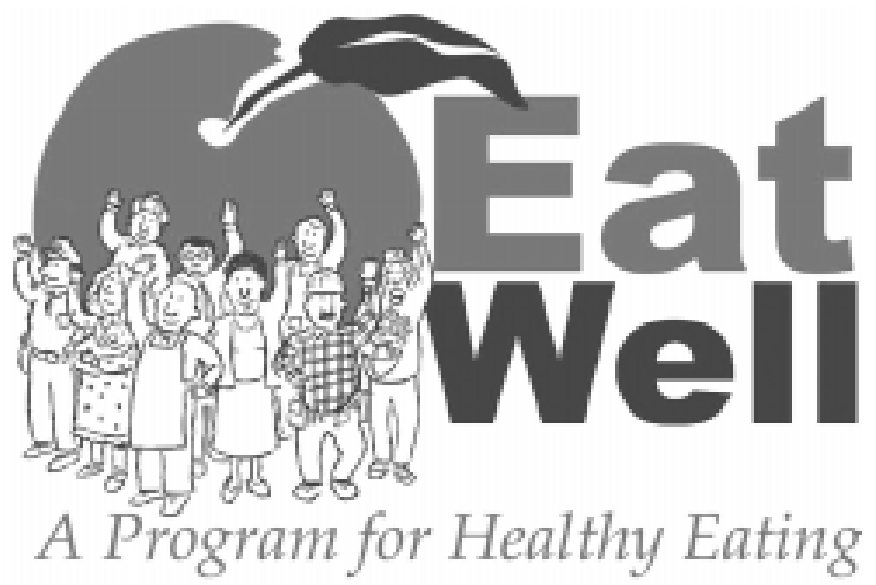

sobre els hàbits alimentaris de la comunitat. Llegir i comprendre

- Lectura de textos de tipologia diversa, en suport paper i digital.

- Ús de les TIC per a la recerca guiada d'informació.

- Lectura i comprensió d'un text sobre els grups d'aliments i extracció de conclusions a partir d'aquests.

Escriure

- Producció d'un informe d'extensió controlada.

- Ús de recursos TIC per establir contactes i comunicar-se en la llengua estrangera.

- Elaboració de preguntes sobre el menjar i escriptura de la resposta.

- Ús de les estructures pròpies de la llengua estrangera en les produccions escrites.

- Realització d'una redacció on es reflexionarà sobre la tasca realitzada.

Els que fan referència a la dimensió literària són:

- Reconeixement i ús del vocabulari i les estructures bàsiques pròpies de la llengua estrangera.

- Recerca de diferents fonts i models per ajudar-se a la composició de textos propis.

- Progressiva autonomia en l'aprenentatge.

- Reconeixement i ús de la llengua estrangera com a eina d'aprenentatge i transmissió de coneixements.

\section{Criteris d'avaluació}

- Reconèixer en llengua anglesa el lèxic pertanyent a la unitat i als hàbits alimentaris de la gent de l'escola i de l'entorn de l'alumne.

- Entonar les produccions orals en llengua anglesa en els petits intercanvis comunicatius per practicar les estructures de la unitat, les expressions i el vocabulari.

- Comunicar les idees pròpies sobre les conclusions extretes als qüestionaris en situacions reals de comunicació.

- Establir un criteri crític per a la diferenciació d'una alimentació saludable a partir de la informació extreta de les enquestes sobre hàbits alimentaris i Internet.

- Confeccionar un informe escrit sobre les conclusions a què han arribat sobre els hàbits alimentaris de les persones de l'escola.

- Fer servir les noves tecnologies a través del programa PowerPoint per a la seva exposició oral a l'aula.

\section{Metodologia de treball}

El treball dels alumnes ha seguit les pautes següents:

1. Buscar informació sobre els hàbits alimentaris dels nens de l'escola, dels mestres i dels pares. 


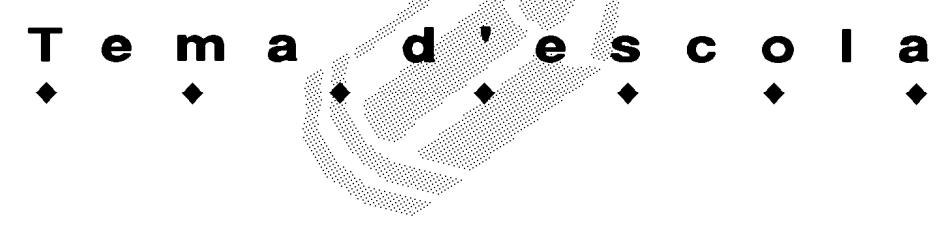

2. Realitzar una sèrie d'enquestes als col-lectius abans esmentats.

3. Fer un buidatge a la classe i comentar els resultats obtinguts per extreure'n conclusions.

4. Redactar un informe i completar la informació de les activitats anteriors amb el suport d'Internet.

5. Fer una presentació per als companys de classe d'altres cursos i per a professors, de manera que puguin expressar en anglès les conclusions a què han arribat.

Els alumnes han seguit aquestes pautes, ja que havien de tenir en compte que s'avaluava la capacitat de treballar en grup per arribar a un objectiu comú: la lectura comprensiva d'un o diversos textos en anglès i la selecció d'informació rellevant, l'expressió escrita en anglès a l'hora de fer preguntes i la redacció d'un petit informe sobre les conclusions extretes. També s'ha tingut en compte l'expressió oral en anglès per expressar les idees a I'hora de fer una petita intervenció oral a classe davant dels companys, així com la discriminació auditiva de sons rellevants en anglès i la selecció d'informació.

La pràctica s'ha dut a terme amb el alumnes durant les sessions següents: tres sessions de 15, 20 i 30 minuts, dues sessions de 60 minuts i una sessió de 20 minuts per presentar els resultats i les conclusions extretes.

Com a estratègia organitzativa per atendre la diversitat, i amb l'objectiu de potenciar l'assoliment de les competències bàsiques per part de tot l'alumnat, la meitat del temps curricular s'ha treballat a l'hora d'anglès amb tot el grup sencer a l'aula ordinària i l'altra meitat del temps s'ha treballat amb mig grups a l'aula d'anglès, on s'ha arribat a les conclusions pertinents i s'ha redactat l'informe. A l'aula d'informàtica s'ha buscat als servidors d'Internet i s'ha fet la presentació en Power Point.

També hi ha una feina extra fora de les aules. Els estudiants han passat una sèrie de preguntes a familiars 0 coneguts, a companys d'escola de diferents edats i a professors del claustre de l'escola.

$\mathrm{Hi}$ ha hagut activitats preparades per dur a terme amb el grup sencer, com ara la decisió de quines preguntes es farien a l'enquesta i feines que havien d'organitzar en petits grups per buscar informació a llibres o a Internet i a l'hora de redactar l'informe.

El mestre d'anglès ha estat sempre el punt de referència dels alumnes i el qui els ha guiat en el procés d'aprenentatge, tot i que l'objectiu prioritari del projecte és incentivar l'autonomia personal dels nens.

Finalment, la producció final s'ha fet a la biblioteca en una presentació en Power Point per a la resta de companys i professors sobre les conclusions extretes i els estudis pertinents. Es deixa la porta oberta perquè en un futur es puguin obrir exposicions als pares involucrats en la realització de diferents parts del projecte.

\section{Activitats d'ensenyament i aprenentatge}

Les activitats de Healthy Eating s'han inclòs dins de la competència comunicativa lingüística i oral, i s'han desenvolupat mitjançant quatre sessions de diferent durada. A continuació s'explicita cadascuna d'aquestes amb més detall:

Sessió 1 (15 minuts)

Activitat: Relació amb els continguts anteriors explicats a la lliçó, explicació de la tasca a realitzar i formació de grups per dur-la a terme.

Continguts: Concepte de dieta saludable. Hàbits alimentaris a la nostra societat. Vocabulari de la unitat: eat, vegetables, carrots, beans, peas, tomatoes, potatoes, salad, fruit, cherries, oranges, pears, bananas, apples, fish, meat, pasta, rice, breakfast, lunch, dinner. Estructures de les unitats: Do you like? / l like.../ / don't like... / l love... / I hate...

Objectius didàctics: Fer petits intercanvis comunicatius (diàlegs) per practicar les estructures de la unitat, les expressions i el vocabulari.

Sessió 2 (20 minuts)

Activitat: Posada en comú de les preguntes que cada grup ha pensat per elaborar el qüestionari. Correc-

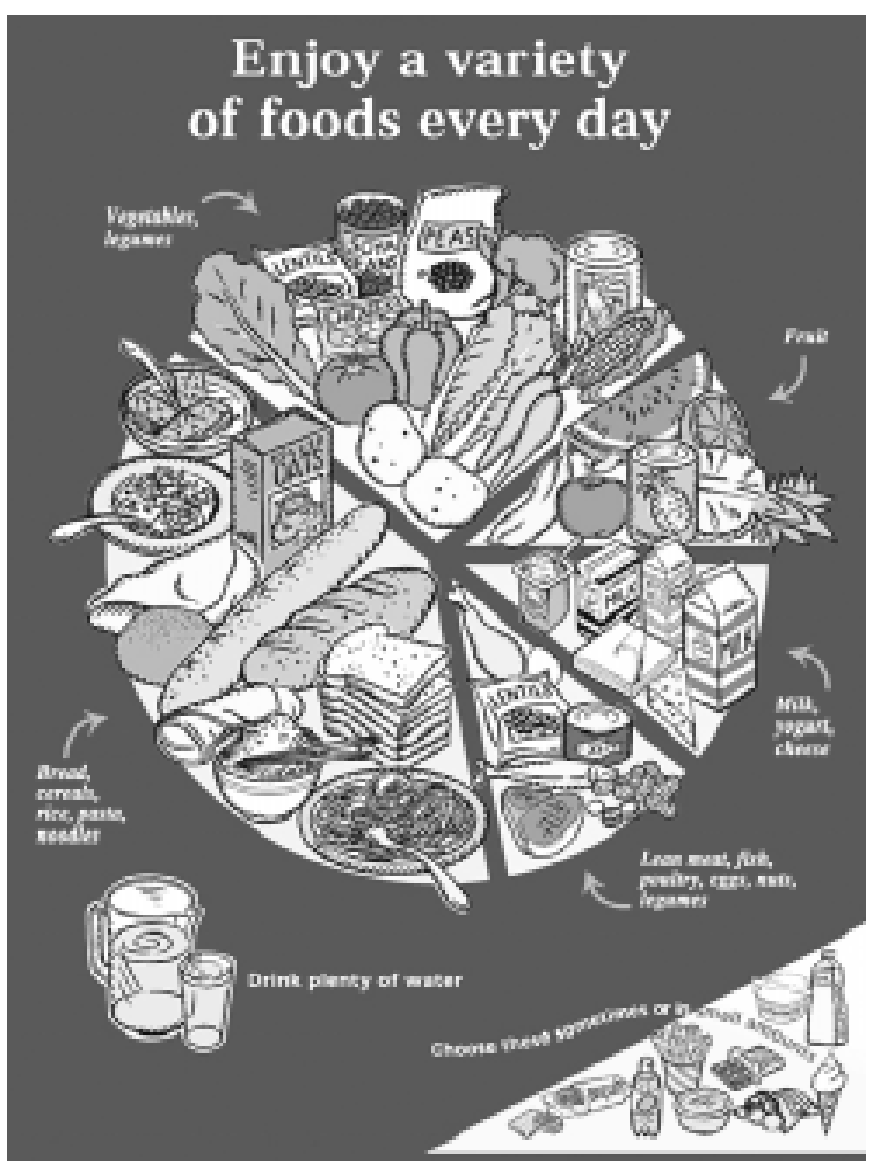




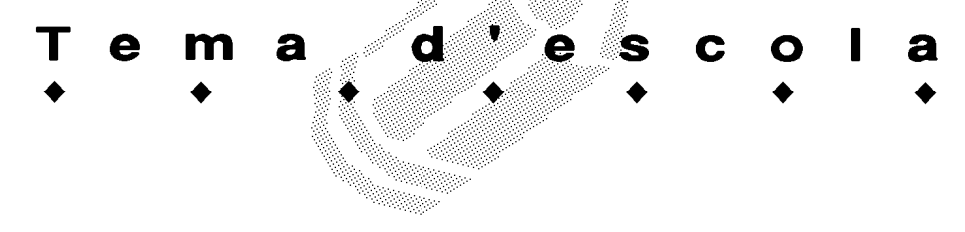

ció de les preguntes. Elaboració del qüestionari.

Material: Fulls de paper per preparar els qüestionaris.

Continguts: Formulació de preguntes i respostes a missatges quotidians: Do you like vegetables? / How many portions of vegetables do you eat a day / week / month?

Objectius didàctics: Expressar-se oralment mitjançant l'entonació corresponent en situacions reals de comunicació. Fer activitats escrites, practicant-ne la comprensió i l'expressió.

Avaluació: Formulació de preguntes en anglès seguint les estructures pròpies de la llengua anglesa.

Sessió 3 (60 minuts)

Activitat: Plasmació dels resultats obtinguts a les enquestes seguint el model de les taules. Exposició dels resultats davant dels companys. Resum de les dades més significatives dels resultats del grup propi.

Material: Taules i graelles.

Continguts: Comprensió global i específica de textos de tipologia i contingut divers. Progressiva autonomia en l'aprenentatge: reflexió sobre el procés, organització i planificació del treball, acceptació de l'error, autocorrecció i autoavaluació.

Objectius didàctics: Buscar i trobar informacions sobre els hàbits alimentaris a l'escola i a l'entorn de l'alumne. Reproduir oralment expressions relacionades amb l'intercanvi social. Extreure informació rellevant a partir d'enquestes sobre hàbits alimentaris.

Sessió 4 (60 minuts)

Activitat: Elaboració de l'informe respecte als hàbits alimentaris de la comunitat educativa. Recerca a Internet sobre altres tipus de dietes i grups alimentaris.

Material: Els qüestionaris omplerts per escriure l'informe. Ordinadors amb connexió a Internet.

Continguts: Comprensió global i específica de textos de tipologia i contingut divers. Ús de les TIC per a la recerca guiada d'informació. Lectura i comprensió d'un text sobre els grups d'aliments. Producció d'un informe seguint uns models treballat a l'aula amb una finalitat comunicativa.

Objectius didàctics: Elaborar un informe sobre la informació que han recopilat a les enquestes i a Internet. Llegir i entendre un text en anglès i identificar-hi informació. Extreure informació rellevant a partir d'enquestes.

Avaluació: Ús de les estructures correctes en les produccions de frases en anglès. Utilització del vocabulari après en la lliçó.

Durant el desenvolupament de l'activitat els alumnes han hagut de seguir les normes següents:

Rules for the team work

- To participate.

- To respect speaking turns.

- To speak with a moderate tone of voice.

- To listen to other classmates' suggestions.

- To organize the roles in the group:

- Speaker: the person in charge of speaking for the group.

- Secretary: The person in charge of writing.

- Organizer: The person in charge of the project material.

A l'annex hi ha el qüestionari que els alumnes han

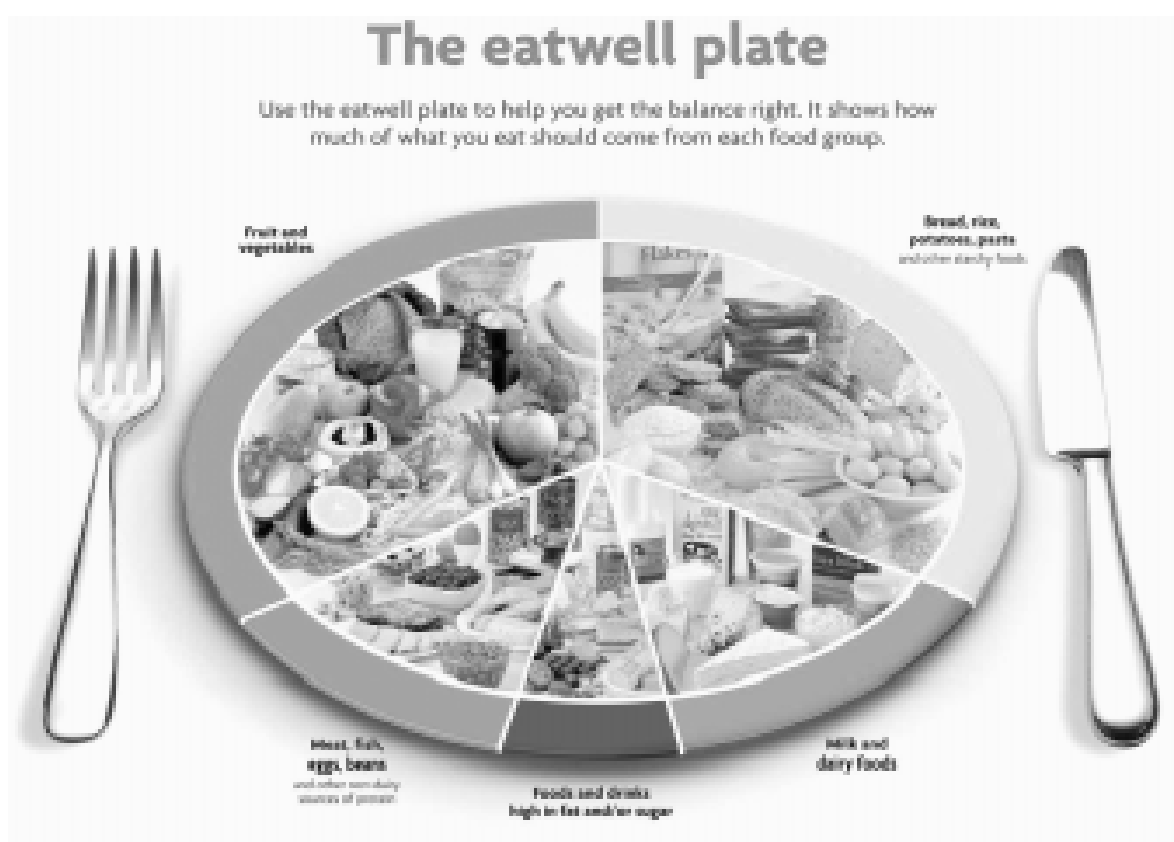




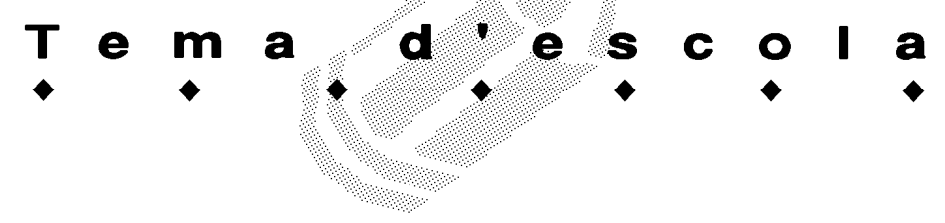

passat a pares, professors i companys, així com els resultats obtinguts.

\section{Conclusió i valoració de l'activitat}

A través d'aquesta pràctica hem descobert que els alumnes s'involucren en el procés de l'aprenentatge de la llengua perquè el projecte sobrepassa els objectius purament linguístics. Els estudiants estan molt motivats donat que han de resoldre per ells mateixos -sota la supervisió del mestre- una tasca que els representa una presa de decisions i responsabilitats en el desenvolupament de l'activitat.

Quant a l'aprenentatge lexical i sintàctic, aquest es va fer a mesura que anaven sorgint les situacions comunicatives que plantejaven i requerien el projecte. El descobriment i assoliment del vocabulari i la gramàtica es justificaven en funció de les necessitats lingüístiques i comunicatives que requeria la tasca.

D'altra banda, en tractar-se d'una tasca en equip, s'ha pogut observar que els alumnes creen forts vincles afectius i assoleixen pautes de treball en grup, sempre molt importants per al treball cooperatiu basat en un projecte d'aquestes característiques.

Com que el projecte anava més enllà de l'aula de llengua anglesa, ha implicat la participació de tot el centre i la col-laboració sempre important dels pares dels alumnes. Els resultats d'aquesta activitat (francament positius tant per a l'alumnat com per al professorat) s'han donat a conèixer a través del bloc de l'escola, amb la qual cosa s'han compartit les vivències $i$ experiències docents amb tota la comunitat educativa.

\section{Referències bibliogràfiques}

GENERALITAT DE CATALUNYA. Marc Europeu Comú de Referència per a les llengües: Aprendre, Ensenyar i Avaluar. 2003. van EK, J.A. The threshold Level. Edit. Pergamon Press. Oxford.1975.

\section{Annex}

\begin{tabular}{|l|l|l|l|l|}
\hline What's your favourite food? & Pasta $\square$ & Vegetables $\square$ & Fish $\square$ & Meat $\square$ \\
\hline $\begin{array}{l}\text { How many pieces of fruit do you } \\
\text { eat during the day? }\end{array}$ & $1 \square$ & $2 \square$ & $3 \square$ & more than 3 \\
\hline Do you eat many sweets? & Always $\square$ & Usually $\square$ & Sometimes $\square$ & Never $\square$ \\
\hline Do you eat many sweets? & Yes, a lot $\square$ & They are ok $\square$ & No, but l eat them $\square$ & No $\square$ \\
\hline What's your favourite vegetable? & Carrots $\square$ & Beans $\square$ & Salad $\square$ & Peas $\square$ \\
\hline What's your favourite fruit? & Oranges $\square$ & Apples $\square$ & Strawberry $\square$ & Pears $\square$ \\
\hline
\end{tabular}

Taula 2. Qüestionari que els alumnes han passat a pares, professors i companys

\begin{tabular}{|l|l|l|l|}
\cline { 2 - 4 } \multicolumn{1}{c|}{} & Teachers & Classmates & Parents \\
\hline What's your favourite food? & Pasta & Teachers & Classmates \\
\hline $\begin{array}{l}\text { How many pieces of fruit do you } \\
\text { eat during the day? }\end{array}$ & 2 & 1 & 1 \\
\hline Do you eat many sweets? & Usually & Always & Sometimes \\
\hline Do you eat many sweets? & Yes, a lot & They are ok & Yes, a lot \\
\hline What's your favourite vegetable? & Carrots and salad Salad & Salad \\
\hline What's your favourite fruit? & Orange & Apple & Banana \\
\hline
\end{tabular}

Taula 3. Resutats del qüestionari que els alumnes han passat a pares, professors i companys 